\title{
Analisis Variasi Temperatur Aktivasi Terhadap Morfologi Permukaan Arang Aktif Tandan Aren (Arenga Pinnata MEER) Dengan Agen Aktivasi Potasium Silikat $\left(\mathrm{K}_{2} \mathrm{SiO}_{3}\right)$
}

\author{
Syukur $^{1)}$ *, Muhammad Anas ${ }^{1)}$, Rosliana Eso ${ }^{1)}$ \\ 1)* Mahasiswa Pendidikan Fisika, Fakultas Keguruan Dan Ilmu Pendidikan, Universitas Halu Oleo \\ ${ }^{2,3)}$ Pendidikan Fisika, Fakultas Keguruan Dan Ilmu Pendidikan, Universitas Halu Oleo \\ *Korespondensi Email: putrasyukur5@gmail.com
}

\begin{abstract}
Abstrak. Penelitian ini bertujuan untuk mengetahui morfologi permukaan arang aktif yang diaktivasi secara kimia dengan agen aktivasi potassium silikat $\left(\mathrm{K}_{2} \mathrm{SiO}_{3}\right)$ dan secara fisika dengan variasi temperatur aktivasi. Karbon aktif tandan aren diperoleh dari tahap karbonasi pada suhu $\left(300{ }^{\circ} \mathrm{C}-400{ }^{\circ} \mathrm{C}\right)$ dan perendaman dengan $\mathrm{K}_{2} \mathrm{SiO}_{3}$ selama 12 jam serta aktivasi fisika selama 30 menit dengan variasi temperatur $600^{\circ} \mathrm{C}, 700^{\circ} \mathrm{C}$, dan $800{ }^{\circ} \mathrm{C}$. morfologi permukaan arang aktif dikarakterisasi menggunakan SEM dan di analysis menggunakan Software Image-J untuk mengetahui luas permukaan pori. Dari analisis, diperoleh luas pori permukaan arang aktif yang hanya diaktivasi secara kimia sebesar $510 \mathrm{~nm}$. Sedangkan dengan aktivasi kimia dilanjutkan dengan pemanasan pada temperatur $600{ }^{\circ} \mathrm{C}, 700{ }^{\circ} \mathrm{C}$, dan 800 ${ }^{\circ} \mathrm{C}$ memiliki luas pori permukaan masing-masing sebesar $535 \mathrm{~nm}, 628 \mathrm{~nm}$, dan $520 \mathrm{~nm}$. Hasil analisis menunjukan luas pori permukaan pada karbon aktif yang paling besar terdapat pada aktivasi $700{ }^{\circ} \mathrm{C}$ yang mencapai $628 \mathrm{~nm}$ dan dikategorikan dalam macropori.
\end{abstract}

Kata Kunci: Arang aktif Tandan Aren, Morfologi Permukaan, Agen Aktivasi dan Temperatur Aktivasi

Abstract. This study aims to determine the surface morphology of activated charcoal which is chemically activated with potassium silicate $\left(\mathrm{K}_{2} \mathrm{SiO}_{3}\right)$ as activation agent and physically with variations of activation temperature. Activated charcoal of sugar palm bunches was obtained from the carbonation stage at temperature $\left(300{ }^{\circ} \mathrm{C}-400{ }^{\circ} \mathrm{C}\right)$ and immersion with $\mathrm{K}_{2} \mathrm{SiO}_{3}$ for 12 hours and physical activation for 30 minutes with variations temperature of $600{ }^{\circ} \mathrm{C}, 700^{\circ} \mathrm{C}$, and $800{ }^{\circ} \mathrm{C}$ The surface morphology of activated charcoal was characterized by using SEM and analyzed by using Image-J software to know the surface area of the pore. The analysis carried out, it was obtained that the surface pore area which was only chemically activated was $510 \mathrm{~nm}$. Whereas with chemical activation followed by heating at temperatures of $600{ }^{\circ} \mathrm{C}, 700^{\circ} \mathrm{C}$, and $800^{\circ} \mathrm{C}$, sequentianlly has surface pore areas of $535 \mathrm{~nm}, 628 \mathrm{~nm}$, and $520 \mathrm{~nm}$. The results of the analysis show that the largest surface pore area on activated carbon is at $700{ }^{\circ} \mathrm{C}$ activation of $628 \mathrm{~nm}$ and it is categorized as macropore.

Key words: Palm Bunch Activated Charcoal, Surface Morphology, Activation Agent and Activation Temperatur.

\section{PENDAHULUAN}

Arang aktif merupakan padatan dengan bahan dasar karbon berpori yang memiliki luas permukaan sangat tinggi yaitu diatas $600 \mathrm{~m}^{2} / \mathrm{g}$ (Sahara,2017). Arang aktif banyak dimanfaatkan dalam berbagai keperluan. antara lain dalam sektor industri, kesehatan, lingkungan, pertanian dan masih banyak lagi. Hal ini dikarenakan arang aktif adalah suatu karbon yang mempunyai kemampuan daya serap yang baik terhadap anion, kation, dan molekul dalam bentuk senyawa organik dan anorganik, baik berupa larutan maupun gas. Bahan yang mengandung banyak karbon terutama yang memiliki pori dapat digunakan untuk membuat arang aktif. Sembiring (2003) menyatakan bahwa bahan baku yang dapat dibuat menjadi arang aktif adalah semua bahan yang mengandung lignoselulosa (lignin dan selulosa). Bahan baku yang berasal dari hewan, tumbuh-tumbuhan, limbah ataupun mineral yang mengandung karbon, 
seperti tandan aren. Tandan aren merupakan salah satu bagian dari pohon aren yang memiliki kandungan selulosa sebesar 33,79\% dan kandungan lignin sebesdar 27,74\% (Sumiyah, 2016). Tandan aren dapat digunakan sebagai bahan pembuatan arang melalui pemanasan yang cukup tinggi. Kemudian, arang diubah menjadi arang aktif melalui proses aktivasi. AktiVasi arang berarti penghilangan zat-zat yang menutupi pori pori pada permukan arang baik secara fisika maupun secara kimia.

Proses aktivasi fisika adalah proses aktivasi yang melibatkan adanya gas pengoksidasi seperti udara pada temperatur rendah, uap, $\mathrm{CO} 2$, atau aliran gas pada temperatur tinggi. Temperatur aktivasi akan mempengaruhi karakteristik karbon aktif yang dihasilkan. Peningkatan temperatur aktivasi akan mereduksi hasil dari karbon aktif. Sedangkan aktivasi kimia adalah proses Aktivasi kimia yang dilakukan dengan mencampur material karbon dengan bahan-bahan kimia atau reagen pengaktif, selanjutnya campuran dikeringkan dan dipanaskan. Aktivator kimia yang digunakan untuk aktivasi arang aktif biasanya berupa asam, basa, atau pun garam. Bahan kimia yang dapat digunakan sebagai pengaktif di antaranya $\mathrm{CaCl}_{2}$, $\mathrm{Ca}(\mathrm{OH})_{2}, \mathrm{NaCl}, \mathrm{MgCl}_{2}, \mathrm{HNO}_{3}, \mathrm{HCl}, \mathrm{Ca}_{3}\left(\mathrm{PO}_{4}\right)_{2}$, $\mathrm{H}_{3} \mathrm{PO}_{4}, \mathrm{ZnCl}_{2}$, dan sebagainya (kurnia,2009). Namun, ada zat aktivator yang belum banyak digunakan dalam aktivasi kimia yakni potasium silikat $\left(\mathrm{K}_{2} \mathrm{SiO}_{3}\right)$ yang digunakan dalam persiapan karbon aktif limbah keratin (limbah bulu kuda) (Kong,2014).

Morfologi permukaan arang aktif dapat memberikan gambaran bagaimana permukaan yang mengalami pembentukan dan perbesaran pori yang baik serta ukuran diameter permukaan pori yang dapat digunakan dalam proses adsorpsi. Cara melihat permukaan pori arang aktif tanda aren ini dengan menggunakan SEM (Scanning Electron Microscope) untuk mengetahui morfologi meliputi bentuk dan ukuran pori. Adrianto (2019) menyatakan bahwa pada suhu suhu $600^{\circ} \mathrm{C}$ dan $700^{\circ} \mathrm{C}$ memperlihatkan permukaan morfologi arang aktif dari tandan aren dengan menggunakan SEM mengalami pembentukan dan perbesaran pori yang baik dengan jumlah pori 678 dan diameter rata-rata $514 \mathrm{~nm}$. Kemudian, pada penilitian yang dilakukan oleh Kong (2014) tentang persiapan karbon aktif limbah tersembunyi dengan menggunakan agen aktivasi potasium silikat $\left(\mathrm{K}_{2} \mathrm{SiO}_{3}\right)$, Luas permukaan spesifik BET dan volume pori karbon aktif yang disiapkan dapat mencapai $2046,12 \mathrm{~m}^{2} / \mathrm{g}$ dan $1,068 \mathrm{~cm}^{2} / \mathrm{g}$. Luas permukaan arang aktif yang diaktivasi menggunakan $\mathrm{K}_{2} \mathrm{SiO}_{3}$ lebih besar dibandingkan dengan $\mathrm{NaoH}$ dan $\mathrm{ZnCl}_{2}$ yang masing-masing hanya mencapai luas permukaan sebesar 1873 $\mathrm{m}^{2} / \mathrm{g}$ dan $1800 \mathrm{~m}^{2} / \mathrm{g}$. Berkaitan uraian diatas, maka penelitian ini dilakukan untuk mengetahui morfologi permukaan dari arang aktif dengan menggunakan agen aktivasi, memperbanyak referensi alternatif pembuatan arang aktif dan analisis karbon aktif dari tandan aren dengan aktivasi fisika dan menggunakan agen aktivasi.

\section{METODE}

Penelitian ini merujuk pada penelitian yang dilakukan oleh Adrianto (2019) dengan material dan prosedur yang sama. Dengan tambahan aktivasi kimia menggunakan larutan potasium silikate $\left(\mathrm{K}_{2} \mathrm{SiO}_{3}\right)$ yang bersifat teknis dengan konsentrasi $90 \%$ sebelum dilakukan aktivasi fisika dengan variasi temperatur. Aktivasi kimia dilakukan dengan mencampurkan arang dengan larutan $\mathrm{K}_{2} \mathrm{SiO}_{3}$ dengan rasio impregnasi 160 :320 (160 g arang: $320 \mathrm{~g} \mathrm{~K}_{2} \mathrm{SiO}_{3}$ ). Kemudian, didiamkan selama 12 jam dan dikeringkan dengan oven pada suhu $105^{\circ} \mathrm{C}$ selama 1 jam. Karakterisasi sampel dilakukan menggunakan SEM dan dianalisis menggunakan softare imagej. 


\section{HASIL DAN PEMBAHASAN}

Adapun hasil karakterisasi SEM dan

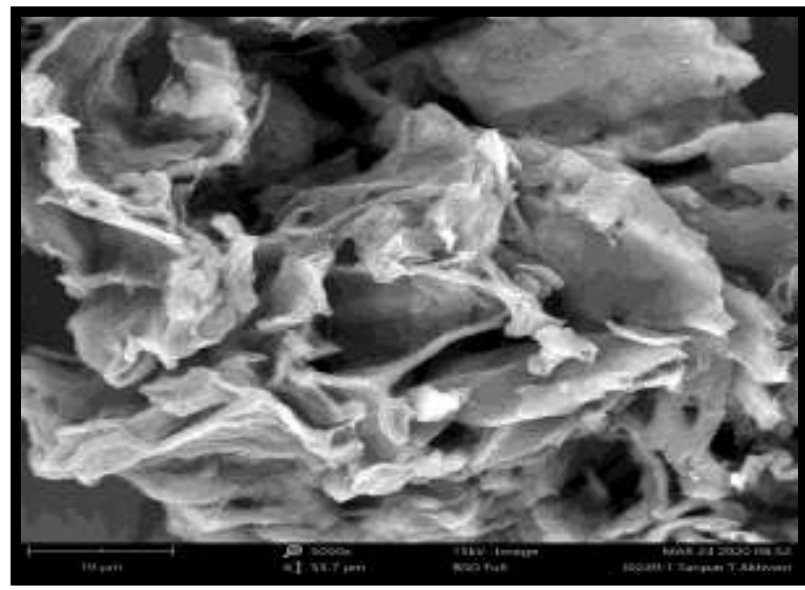

(a)

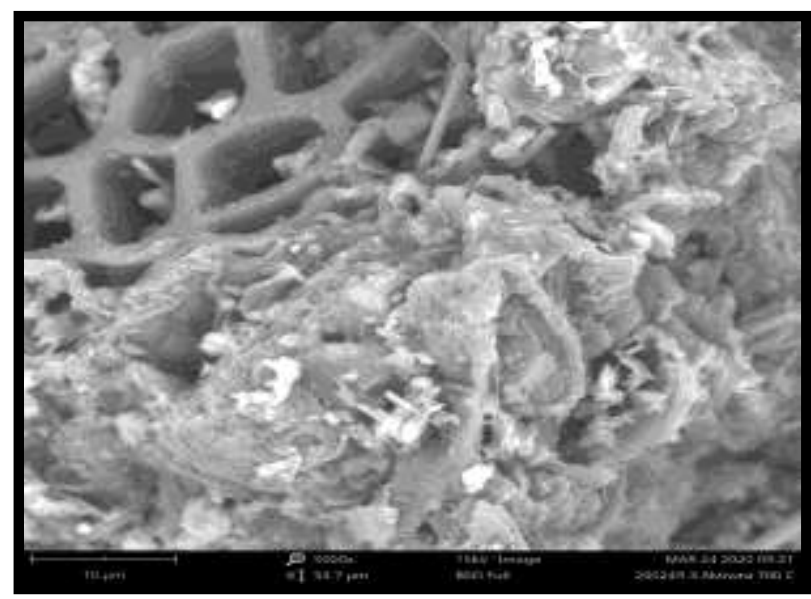

(c) analisis Software Image-j untuk permukaan arang aktif adalah sebagai berikut :

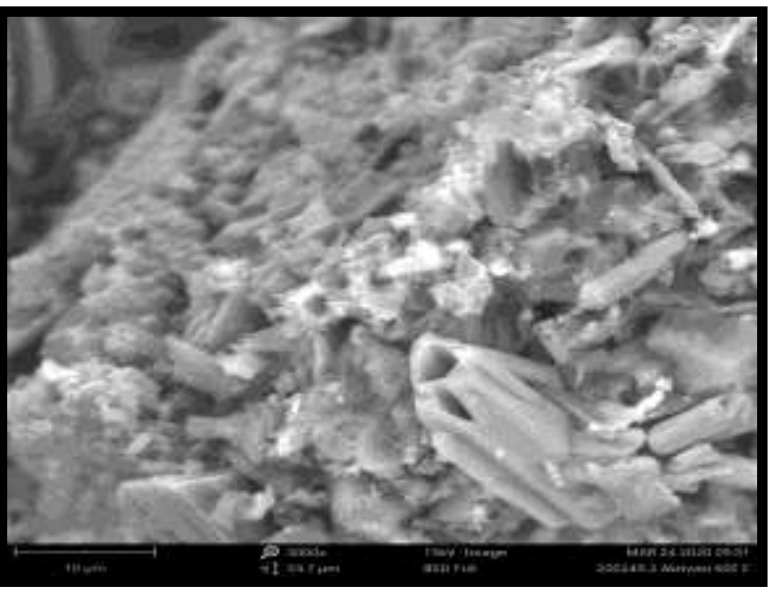

(b)

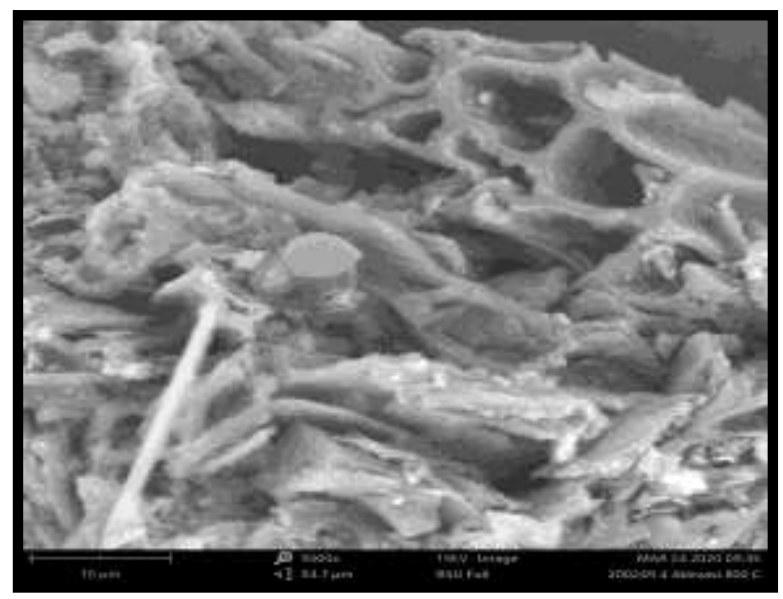

(d)

Gambar 1. Hasil Karakterisasi Sem Dari Arang Aktif Tanda Aren Pada Perbesaran 5000x Dengan Variasi Temperature Aktivasi (a) tanpa aktivavi, (b) aktivasi $600^{\circ} \mathrm{c}$, (c) aktivasi $700^{\circ} \mathrm{c}$, dan (d) aktivasi $800^{\circ} \mathrm{C}$

\section{Pembahasan}

Karbon aktif adalah suatu bahan yang berupa karbon amorf yang mempunyai luas permukaan yang sangat besar. Karbon aktif diperoleh dari arang yang telah diaktivasi. Dimana, tahap aktivasi merupakan salah satu tahap pembuatan karbon akif yang dilakukan untuk memperbesar pori dengan cara memecah ikatan hidrokarbon atau mengoksidasi molekul-molekul permukaan sehingga arang mengalami perubahan baik fisika maupun kimia yaitu luas pori permukaannya bertambah besar dan berpengaruh terhadap daya adsorpsi (Kurnia,2009).

Karakterisasi morfologi permukaan arang aktif tandan aren yang hanya diaktivasi dengan larutan $\mathrm{K}_{2} \mathrm{SiO}_{3}$ dan dengan aktivasi fisika pada suhu 
$600^{\circ} \mathrm{C}, \quad 700^{\circ} \mathrm{C}$ dan $800^{\circ} \mathrm{C}$ dilakukan dengan menggunakan SEM dan dianalisis menggunakan software imagej. Berdasarkan penelitian yang telah dilakukan, aktivasi kimia dengan larutan $\mathrm{K}_{2} \mathrm{SiO}_{3}$ ditunjukan pada Gambar 4.1 yang memperlihatkan morfologi permukaan arang aktif dengan pori-pori yang sudah mulai terbentuk. Namun, pori yang terbentuk masih terdapat penyumbatan. Hal ini dikarenakan aktivasi kimia memiliki perlakuan khusus sebelum dipanaskan yaitu direndam larutan kimia agar pengotor pada permukaan arang setelah dikarbonisasi terlepas atau terurai dengan larutan kimia (Masthura,2018). Hasil aktivasi dengan larutan $\mathrm{K}_{2} \mathrm{SiO}_{3}$, lebih baik jika disandingkan dengan arang aktif tandan aren yang tidak diaktivasi sama sekali pada penelitian yang dilakukan oleh Nanang (2019). Dimana, hasil analisis arang yang tidak diaktivasi belum mempelihatkan permukaan pori yang terbuka. Selanjutnya, arang yang diaktivasi pada suhu $600^{\circ} \mathrm{C}$ dengan agen aktivasi terlihat pada gambar 4.2, menunjukan bentuk permukaan pori yang mulai terbuka dengan ukuran yang pori lebih besar dibandingan dengan arang tanpa suhu aktivasi. Hal ini disebabkan oleh zak aktivator yang berfungsi sebagai reagen pengaktif dan zat ini akan mengaktifkan atom-atom karbon sehingga daya serapnya menjadi lebih baik. Haryati (2017) menyatakan bahwa zat aktifator bersifat mengikat air yang menyebabkan air yang terikat kuat pada pori-pori karbon yang tidak hilang pada saat karbonisasi menjadi lepas. Selanjutnya zat aktifator tersebut akan memasuki pori dan membuka permukaan arang yang tertutup. Dengan demikian pada saat dilakukan pemanasan, senyawa pengotor yang berada dalam pori menjadi lebih mudah terserap sehingga luas pori permukaan karbon aktif semakin besar. Kemudian, pada suhu aktivasi $700^{\circ} \mathrm{C}$ dengan agen aktivasi memperlihatkan pori yang terbentuk lebih banyak dari aktivasi yang lain baik dari segi jumlah pori maupun luas pori. Semakin banyak jumlah pori yang dihasilkan maka luas permukaan pori juga akan semakin besar (Efendi,2016). Adanya interaksi antara zat pengaktivasi dengan struktur atom-atom karbon hasil karbonisasi adalah mekanisme dari proses aktivasi. Selama aktivasi, karbon dipanaskan dan akan menambah jumlah dan luas permukaan. selain itu, aktivator dapat meningkatkan keaktifan sehingga arang mengalami perubahan sifat, baik fisika maupun kimia, yaitu luas permukaannya bertambah besar dan berpengaruh terhadap daya adsorpsi (Sembiring, 2003). Sebagai contoh, Daya adsorpsi karbon aktif terhadap iod memiliki korelasi dengan luas permukaan dari karbon aktif. Semakin besar angka iod maka semakin besar kemampuannya dalam adsorbs atau zat terlarut Untuk meningkatkan jumlah yodium, gaya serap terhadap Iod semakin besar dengan kenaikan suhu, ini berarti bahwa kualitas arang aktif akan meningkatkan adsorpsi warna.

Peningkatan luas pori permukaan pada suhu $700^{\circ} \mathrm{C}$ dengan agen aktivasi sedangkan pada suhu $800^{\circ} \mathrm{C}$ dengan agen aktivasi mengalami penurunan disebabkan oleh pelepasan zat yang mudah menguap dan korosi $\mathrm{K}_{2} \mathrm{SiO}_{3}$. Ketika suhu aktivasi rendah, peran $\mathrm{K}_{2} \mathrm{SiO}_{3}$ lemah dan hanya bahan bakunya yang dikarbonisasi. $\mathrm{K}_{2} \mathrm{SiO}_{3}$ mulai mempromosikan pembukaan mikropori saat suhu meningkat dari $400^{\circ} \mathrm{C}$ menjadi $700^{\circ} \mathrm{C}$. Namun, ketika suhu tinggi, parsial mikropori dapat digabung menjadi mesopori atau makropori sebagai akibat dari korosi dan hal-hal yang mudah menguap. Selain itu, volatilisasi atom karbon pada lapisan kristal semakin intensif (Kong,2014). Hal ini sesuai pada suhu $800^{\circ} \mathrm{C}$ yang mengalami penurunan jumlah pori dan luas permukaan pori. Hasil ini diperkuat pula dengan pernyatan Efendi (2016) pada penelitiannya tentang pengaruh suhu aktivasi terhadap morfologi dan jumlah pori karbon aktif tempurung kemiri sebagai elektroda, bahwa mengecilnya ukuran pori disebabkan oleh naiknya energi panas. Dimana, energi panas yang semakin besar mengakibatkan partikel bergerak lebih cepat sehingga bertumbukan satu sama lain. Akibat dari tumbukan ini partikel terpecah menjadi lebih kecil sehingga menghasilkan pori yang lebih kecil

Hasil aktivasi yang telah dilakukan dianalisis menggunakan software imagej, dengan suhu Aktivasi $700^{\circ} \mathrm{C}$ dengan agen aktivasi $\mathrm{K}_{2} \mathrm{SiO}_{3}$ memiliki jumlah pori yang paling banyak dan luas pori yang paling besar dari semua temperatur aktivasi (terlihat pada Tabel 4.1). Jumlah pori yang terbentuk akan meningkatkan luas 
permukaan pori dari karbon aktif. Semakin banyak jumlah pori yang dihasilkan maka luas permukaan pori juga akan semakin besar (Efendi, 2016). Hal ini didukung oleh penelitian yang dilakukan oleh Kong, dkk (2014) yang memperoleh luas pori permukaan terbaik pada suhu $700^{\circ} \mathrm{C}$ dengan agen aktivasi yang sama yakni potasium silikat. Selain itu penelitian yang sama tentang arang aktif tandan aren yang diaktivasi secara fisika yang dilakukan oleh Nanang (2019), yang memperoleh luas pori permukaan terbaik pada suhu $700^{\circ} \mathrm{C}$ sedangkan pada suhu $800^{\circ} \mathrm{C}$ mengalami pengurangan jumlah pori dan penurunan luas permukaan pori.

Shofa (2012), mengemukakan bahwa poripori yang berukuran lebih dari $50 \mathrm{~nm}$ disebut macropore, sedangkan pori dengan ukuran $2 \mathrm{~nm}-$ $50 \mathrm{~nm}$ dikategorikan mesopores, dan dibawah 2 $\mathrm{nm}$ disebut micropores. Sehingga, dapat dikatakan baha pori yang terbentuk pada permukaan arang aktif tandan aren yang hanya diaktivasi dengan larutan $\mathrm{K}_{2} \mathrm{SiO}_{3}$ dan dengan aktivasi fisika pada suhu $600^{\circ} \mathrm{C}, 700^{\circ} \mathrm{C}$ dan $800^{\circ} \mathrm{C}$ digolongkan pada kategori macropori.

\section{KESIMPULAN}

Berdasarkan penelitian yang telah dilakukan, maka dapat disimpulkan bahwa semakin tinggi suhu aktivasi, maka luas permukaan pori arang aktif tandan aren akan bertambah besar. Dengan luas pori permukaan maksimum terdapat pada suhu $700^{\circ} \mathrm{C}$ yakni jumlah pori sebanyak 285 dan diameter ratarata sebesar $628 \mathrm{~nm}$.

\section{SARAN}

Adapun saran yang diharapkan agar dilakukan kembali penelitian mengenain tandan aren dengan agen aktivasi potasiun silikat dengan variasi konsetrasi serta dengan menggunakan bahan activator yang lain.

\section{DAFTAR PUSTAKA}

Adrianto,N. 2019. Analisis Morfologi Permukaan Arang Aktif Tandan Aren (Arengga Pinnata Merr) Yang Diaktivasi Menggunakan Tanur Dan Microwave . FKIP.UHO.Kendari. Skripsi
Effendi,Z. Astuti. 2016. Pengaruh Suhu Aktivasi Terhadap Morfologi dan Jumlah Pori Karbon Aktif Tempurung Kemiri sebagai Elektroda . Jurusan Fisika FMIPA. Universitas Andalas. Padang

Haryati, S. Adellina, T. Lisa, A. 2012. Pembuatan Karbon Aktif Dari Kulit Kayu Gelam (Melaleuca Leucadendron) Yang Berasal Dari Tanjung Api-Api Sumatera Selatan. Jurusan Teknik Kimia. Fakultas Teknik. Universitas Sriwijaya

Kong, J. Qinyan, Y. Baoyu, G. Qian, L. Yan, W. Huu, H. Wenshan, G. 2014. Porous structure and adsorptive properties of hide waste activated carbons prepared via potassium silicate activation. School of Civil and Environmental Engineering. University of Technology. Broadway,. Sydney. Australia.

Kurnia, D. Arif, N. Edwin, P. Pembuatan Karbon Aktif Dari Kulit Ubi Kayu (Mannihot Esculenta) .Teknik Kimia. Fakultas Teknik. Universitas Sriwijaya

Masthura. Zulkarnain. 2018. Karakterisasi Mikrostruktur Karbon Aktif Tempurung Kelapa dan Kayu Bakau. Program Studi Fisika Fakultas Sains dan Teknologi. UIN. Sumatera Utara. Medan

Sahara, E. Wahyu D,S. Putu, A, S. 2017. Pembuatan Dan Karakterisasi Arang Aktif Dari Batang Tanaman Gumitir (Tagetes Erecta) Yang Diaktivasi Dengan $\mathrm{KOH}$. Jurusan Kimia FMIPA. Universitas Udayana. Bukit Jimbara.

Sembiring, M. T. Sinaga, T. S.2003. Arang Aktif (Pengenalan dan Proses Pembuatannya). Sumatera Utara Fakultas Teknik, Universitas Sumatera Utara.

Shofa. 2012. Skripsi: Pembuatan Karbon Aktif Berbahan Baku Ampas Tahu dengan Aktivasi Kaliun Hidroksida. Universitas Indonesia. Depok.

Sumaiyah, W. Basuki. Karsono.2016. Utilization of Microcrystalline Cellulose of Sugar Palm Bunches (Arengapinnata (Wurmb) Merr.) asExcipients Tablet Direct Compression. Faculty of Pharmacy. University of Sumatera Utara. Indonesia. 